P Eva Julianti, Dlis Firmansyah, Asmawi Moch. The Effect of Physical Activities on Physical Education Learning Outcomes. Journal of Education, Health and Sport. 2019;9(11):100-109. eISSN 2391-8306. DOI http://dx.doi.org/10.12775/JEHS.2019.09.11.007 https://apcz.umk.pl/czasopisma/index.php/JEHS/article/view/JEHS.2019.09.11.007

https://zenodo.org/record/3540932

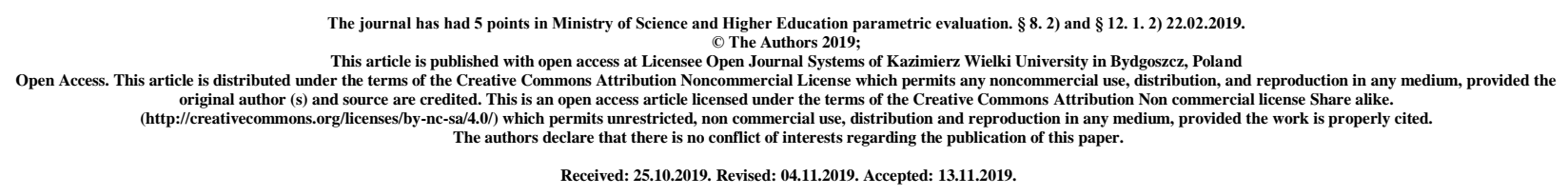

\title{
The Effect of Physical Activities on Physical Education Learning Outcomes
}

\author{
Eva Julianti P, Firmansyah Dlis, Moch Asmawi \\ Sport Science Study Program, State University of Jakarta, Indonesia \\ Email: eyulianti@unj.ac.id
}

\begin{abstract}
This study aimed to find the effect of physical activity on academic performance of physical education. The research method used in this research is quantitative approach, survey method with test and measurement technique. The population of the research was students at a public secondary school in East Jakarta, and 216 students of 6 classes grade eight participating in this research. There is a positive influence of physical activity on student learning outcome of physical education. Physical activity has a direct positive effect on learning outcomes of physical education. This means that increasing physical activity will lead to an increase in physical education learning outcomes. Implication of the present study is that efforts can be made to improve learning outcomes physical education through structured physical activity, by providing physical activities, games and sports chosen to achieve educational goals.
\end{abstract}

Keywords: academic achievement; motor ability; METs; MVPA

\section{INTRODUCTION}

Education is expected to have an impact on learning outcomes, namely changes in student behavior. This change in behavior should embrace all the potential in children that can be developed through education. One of them is physical education, which is an integral part of overall education, aims to develop aspects of physical fitness, movement skills, critical thinking skills, social skills, reasoning, emotional stability, action moral, aspects of a healthy lifestyle and the introduction of a clean environment through selected physical, sporting and health activities that are planned systematically in order to achieve national education goals. Physical education is an important part of the education system (Juliantine, 2016). Therefore, physical education is presented to encourage the development of motor skills, physical abilities, knowledge, reasoning, appreciation of values (attitudes - mental emotional - spiritual - social), and habituation of healthy lifestyles that lead to stimulate balanced and overall growth and development. Physical education can be seen from various meanings that are closely related to pleasant personal 
impressions as well as various expressions that are creative, skillfully innovative, have physical fitness, healthy living habits and have knowledge and understanding of human motion.

Some problems that become phenomena to look for the effect of physical activity on learning outcomes, among others, there are differences in Minimum Learning Completion (MLC) in assessment, there are students who have not yet reached the minimum learning outcome in physical education subjects. Also identified are the problems faced by teachers in conducting performance-based assessments as well as the differences in teachers in determining the components of physical education learning outcomes assessment. The next problem is the percentage of students who have less physical activity than those who have enough physical activity, so the WHO does not meet the minimum physical activity criteria recommended by WHO. As well as the lack of physical activity of students, where students are lazy to move and follow or do mobile assignments and are fully involved in activities in the field during physical education lessons. In accordance with the things stated above, this study aims to find and measure the effect of physical activity on physical education learning outcomes. Physical education is an integral part of the curriculum in secondary school which emphasizes efforts to stimulate, increase growth and physical, mental, emotional, and social development of students. According to Nichols (2001), physical education is the only part of the curriculum that gives attention to motor skills and skills, studies human motion and gives space and facilitates movement to develop. Even physical education in secondary school is an important moment in the development of children's attitudes to active participation in sports / other motion activities throughout their lives.

Furthermore, Baumgartner (2006) explained that physical education is a process of a person as an individual and a member of the community carried out consciously and systematically through various activities in order to acquire physical abilities and skills, growth, intelligence, and character formation. Physical education as a part that contributes to education in general. Through the provision of hands-on experiences in order to help the growth and development of children that are total or comprehensive. Pettifor in Kohl and Cook (2013) said that physical education gives students the opportunity to practice an active and healthy lifestyle by providing a range of neat and systematic learning experiences. That is, physical education provides space to shape students as a whole child and is directed at the development of cognitive, affective and psychomotor aspects. In the other side the physical education program in secondary school must be followed by all students, starting from grade seven to grade nine, given with three hours of study time per week consisting of mandatory activities and optional activities.

In the middle of the semester and at the end of the semester, the teacher will present the results of evaluating student achievements in each lesson, including physical education. Assessment is the process of gathering and processing information to measure the achievement of student learning outcomes. Assessment of physical education learning outcomes generally uses assessment methods based on practical tests, observations, written tests, portfolios, individual or group assignments, oral tests, and journals. Physical education assessment components that can be carried out by physical education teachers, such as summative assessments from South Carolina (South Carolina Physical Education Assessment Program, 2007) and New York (New York State Education Department (Mercier \& Doolittle, 2013) summarized by Mercier and Doolittle (2013), consisting of: Fitness Development (Physical fitness test with normative score), knowledge of fitness (written test), Personal Fitness Planning (project assignments), daily physical activities or Moderate-to-Vigorous Physical Activity (filling log-book); ability or motor skills (teacher observations with rubrics); students' knowledge of physical skills and physical or sports activities 
(written tests); attitudes and behavior of students in Activity Settings (teacher observations with rubrics); as well as student knowledge about Personal and Social Skills in Activity Settings (written test). Determination of learning outcomes, educators or schools must also determine the criteria for deciding whether a student has achieved Minimal Learning Completion or not. , and sustainable, in order to reveal various aspects needed in making decisions.

The regulation of the Indonesian Minister of Education and Culture concerning Education Assessment Standards states that assessment of learning outcomes by educators serves to monitor learning progress, monitor learning outcomes, and detect the need for continuous improvement in student learning outcomes. Implementation of implementation the 2013 curriculum uses authentic assessment (authentic assessment). Authentic assessment is an assessment carried out comprehensively to assess starting from the input (input), process, and output (output) of learning or a significant measurement of student learning outcomes for the realm of attitudes, skills, and knowledge. According to the Educational Assessment Standards mentioned above, the teacher evaluates skills competency through performance appraisal, which is an assessment that requires students to demonstrate a certain competency using practice tests, projects, and portfolio assessment. However, not all physical education teachers do performance evaluations.

Based on previous research found the phenomenon that physical education teachers knew about performance-based assessment, but not all understood performance-based assessment. Another finding is that physical education teachers do not carry out assessments at the beginning of learning and do a little assessment during learning, but many do in the middle and the end of the semester. The implementation of assessment uses standardized tests, uses observations and uses tests and observations. There are even teachers who do not do an assessment because they think students have not received the material to be assessed. In the other side, the results of the interview, physical education teachers in a state junior high school in East Jakarta have used authentic assessment and to assess skills using performance-based assessment. Physical education learning outcomes in the daily assessment in the first mid-semester, student learning outcomes indicate there are $57.41 \%$ who have not reached the Minimal Learning Completion (MLC). While $42.59 \%$ of students have reached MLC. The difference in learning outcomes becomes interesting for researchers to see the factors that influence the differences. Furthermore, in conducting an assessment, several factors are considered to be determinants of student learning outcomes and to be able to achieve MLC in physical education, including the level of student physical activity (Bellarin, 2016; Centers for Disease Control and Prevention, 2010; Kyan, Takakura, \& Miyagi , 2018; Resaland et al., 2016).

As we know, there are factors that also have a relationship with learning outcomes of physical education are motor skills (Chen, Mason, Hypnar, \& Bennett, 2016; Ericsson, 2014; Magistro, Bardaglio, \& Rabaglietti, 2015; Singh, 2013; van der Fels et al., 2015). In literature review, also shows learning outcomes are also influenced by teachers through classroom management (Cothran, 2015; Bevans, Fitzpatrick, Sanchez, Riley, \& Forrest, 2010). Referring to the factors that are the basis of assessment in learning outcomes physical education, physical activity in addition to being one of the assessments also has a relationship with learning outcomes. This is consistent with research conducted by Megan J. Hylok. Hylok's research (J Hylok, 2011) using a mix method combining quantitative and qualitative results, found social influence, self-efficacy, support, environment, academics, and motivation have the greatest statistical and substantive influence on physical activity. After conducting the first to third analysis, Hylok stated in the 
fourth analysis it was known that more students felt there was a relationship between physical activity and academic achievement.

Based on Nicole J. Smith et al. (2015) shows physical activity is significantly different between modified schools and traditional schools. Students who attend traditional schools engage in higher physical activity in sports lessons. Physical activity is positively related to fitness and the teacher's invitation to students to actively move. In line with Smith et al. (2015), Burhein, (2017) states children develop, grow and learn through physical activity, so that moving plays a very important role in the total child development process. Moving is a tool/media for children to explore, make friends and face the surrounding environment. By moving, a child processes to develop their potential. In this case the main function of parents and teachers is to help children develop this potential. The development of children in relation to this is all functional changes in each individual, which is a product of heredity (genes), growth, maturity, experience and adaptation. Human development itself is classified based on age stages, where each stage shows changes in behavior and growth. At each stage of its development, children in general are at the stage of education according to their classification of development. Several of theories tend to link the entire achievement of learning outcomes with motor development, rather than seeing motion activities as a tool for learning. According to Otero and Perez (2015) which reinforces Cratty's (1973) opinion that existing theories state that, if certain motion activities are used appropriately, it can prepare children to gain intelligence in spelling, reading and activity similar in the early days of school. This can be true, if the activity of motion is related to the process of gaining intelligence.

Normal children have a brain, which makes it able to think and process ideas. Motion itself cannot guarantee intellectual intelligence. But the activity of motion and intellectual processes together can support intelligence. Based on this, in addition to parents, teachers also have a very large role in the formation of intelligence, especially when children are in school. The Committee on Physical Activity and Physical Education in the School Environment (2013) reviews recent research findings regarding the contribution of involvement in physical activity and the achievement of physical fitness levels that improve health on cognitive and brain health in children. Correlational research that examines the relationship between learning outcomes, physical fitness, and physical activity. Children respond faster and with greater accuracy to various cognitive tasks after participating in physical activity activities (Ellemberg \& St-LouisDeschênes, 2010; Pesce, Crova, Cereatti, Casella, \& Bellucci, 2009; Tomporowski, 2003; ).

When children who participate in 30 minutes of aerobic physical activity are compared with children who watch television for the same amount of time, children who do physical activity are cognitively outperformed by children who watch television. (Ellemberg \& St-Louis-Deschênes, 2010). If physical activity is used as a resting activity between class hours, it can increase student attention in lessons (Bartholomew \& Jowers, 2011); and can improve On Task Behavior (Mahar et al., 2006) (Baumgartner, Jackson, Mahar, \& Rowe, 2006) and can even improve learning outcomes (Donnelly \& Lambourne, 2011). The National Report on the results of the Basic Health Research in 2018, showed that there were 33.5\% of people in Indonesia aged $\geq 10$ years who were classified as less active and in Jakarta there were $47.8 \%$ of the people classified as less active. In the 10-14 years age group who have a less active lifestyle, the percentage is $64.4 \%$, and in the 15-24 years age group is $49.6 \%$. These results are directly proportional to the results of questionnaires and observations made by researchers on students of one state junior high school in East Jakarta, $67.7 \%$ of students who use their free time outside school time, 
extracurricular and other tutoring, to sleep or play gadgets, watching TV and do other light activities.

The results of the questionnaire show students have inactive behavior when at home. Likewise, from the results of observations when at school, showing less active behavior, where students during recess only sit and chat in and outside the classroom. The experiences of motion obtained by children contribute to the development of cognitive and perceptual domains. It is assumed that, if physical activity plays an important role in the cognitive and perceptual development of children, and both contribute to academic success, then there is an influence of physical activity with academic success in this case physical education learning outcomes. Physical education using physical activity as a medium of the learning process, does not mean ignoring the development of cognitive and affective parts, but through the accompanying impact of physical activity can directly contribute to the achievement of goals in the cognitive and affective domains. Physical education is the process of education about and through physical activities, games, and sports chosen to achieve educational goals. One factor that affects physical activity is mental health. (Centers for Disease Control and Prevention, 2010) Where physical activity can relieve symptoms of depression and improve one's mood. So, if students have good activities, it will have an impact on improving learning outcomes while at school, especially on physical education subjects. Thus, it is suspected that there is a direct influence between physical activity and physical education learning outcomes.

\section{METHOD}

Physical education learning outcomes are scores of changes experienced by students through a physical activity to achieve the learning objectives to be achieved because of the planned learning process. Physical education learning outcomes are grades on student learning outcomes reports in odd semester.

While physical activity is any body movement produced by skeletal muscle that requires energy expenditure, with indicators: (a) activity at home; (b) activities at school; (c) leisure / leisure activities. Physical activity was measured using an instrument consisting of 15 questions to measure physical activity at home, 11 questions for activities at school and 9 questions for physical activity at leisure. The criteria used to test the validity of items using the reference $r$ table with $\alpha=0.05$, if $r$ count is greater than or equal to $r$ table then the instrument items are considered valid. Conversely, if the $r$ count is smaller than or equal to $r$ table, then the instrument items are considered invalid and subsequently not used. As many as 216 students filled out the questionnaire given, to recall physical activities during the previous 7 days. The results are then scored according to established norms based on the level of physical activity. Where one metabolic equivalents (METs) is the same as sitting activity without doing activities. Here is a table measuring the level of physical activity for a healthy adult. Inferential analysis is used to test hypotheses. Indicators in each variable are calculated using analysis prerequisite tests, linearity testing, to hypothesis testing and path coefficients with SPSS for Windows Ver. 25.00 
Table 1 Physical Activity Level

\begin{tabular}{|c|c|c|}
\hline $\begin{array}{c}\text { Light } \\
<3.0 \text { METs }\end{array}$ & $\begin{array}{l}\text { Moderate } \\
\text { 3.0-6.0 METs }\end{array}$ & $\begin{array}{c}\text { Vigorous } \\
>\text { 6.0 METs }\end{array}$ \\
\hline Walking Slowly & $\begin{array}{l}\text { Walking-Very brisk (4 } \\
\text { mph) }\end{array}$ & Walking/hiking \\
\hline Sitting-using computer & $\begin{array}{l}\text { Cleaning-heavy (washing } \\
\text { windows, vacuuming, } \\
\text { mopping) }\end{array}$ & Jogging at $6 \mathrm{mph}$ \\
\hline $\begin{array}{l}\text { Standing-light work } \\
\text { (cooking, washing) }\end{array}$ & $\begin{array}{l}\text { Moving lawn (walking } \\
\text { power mover) }\end{array}$ & Shoveling \\
\hline Fishing-sitting & $\begin{array}{l}\text { Bicycling-light effort (10- } \\
12 \mathrm{mph} \text { ) }\end{array}$ & Carrying-heavy loads \\
\hline Playing most instruments & $\begin{array}{l}\text { Badminton-recreational } \\
\text { Tennis-doubles }\end{array}$ & $\begin{array}{l}\text { Bicycling fast }(14-16 \mathrm{mph}) \\
\text { Basketball game } \\
\text { Soccer game } \\
\text { Tennis-single }\end{array}$ \\
\hline
\end{tabular}

Source: School of Public Health - Harvard T.H.Chan

\section{RESULTS}

Descriptions of each variable are performed using descriptive statistics which include measures of concentration and data distribution. The size of the concentration of data includes the mean, mode and median values. The size of the data spread includes the range and standard deviations of the data and the variance of the data. The description of the data includes data on physical education learning outcomes (Y) which are referred to as endogenous variables, physical activity variables $(\mathrm{X})$ as exogenous variables. The data is then processed statistically into a frequency distribution list, the number of classes is calculated according to the Sturges rule, obtained nine classes with a maximum score of 96 and a minimum score of 70, so that the range of scores is 26.

The results of the calculation of the data are obtained an average of 81.32; standard deviation of 4.89; variance of 23.9410; a median of 81.5; and mode of 82. Grouping data on physical education learning outcomes can be seen in the frequency distribution table as follows.

Table 2 Frequency Distribution of Physical Education Learning Outcomes

\begin{tabular}{|c|c|c|c|c|c|c|c|c|}
\hline \multirow{2}{*}{$\begin{array}{c}\text { N } \\
\text { o }\end{array}$} & \multicolumn{2}{|c|}{ Interval } & \multicolumn{2}{c|}{ Class Limit } & \multicolumn{3}{c|}{ Frequency } \\
\cline { 5 - 9 } & \multicolumn{2}{|c|}{} & Below & Upper & $\begin{array}{c}\text { Absolut } \\
\text { e }\end{array}$ & Relative & $\begin{array}{l}\text { Cumulativ } \\
\text { e }\end{array}$ \\
\hline 1 & 70 & - & 72 & 69,5 & 72,5 & 8 & $3,70 \%$ & $3,70 \%$ \\
\hline 2 & 73 & - & 75 & 72,5 & 75,5 & 18 & $8,33 \%$ & $12,04 \%$ \\
\hline 3 & 76 & - & 78 & 75,5 & 78,5 & 33 & $15,28 \%$ & $27,31 \%$ \\
\hline 4 & 79 & - & 81 & 78,5 & 81,5 & 49 & $22,69 \%$ & $50,00 \%$ \\
\hline 5 & 82 & - & 84 & 81,5 & 84,5 & 57 & $26,39 \%$ & $76,39 \%$ \\
\hline 6 & 85 & - & 87 & 84,5 & 87,5 & 32 & $14,81 \%$ & $91,20 \%$ \\
\hline 7 & 88 & - & 90 & 87,5 & 90,5 & 9 & $4,17 \%$ & $95,37 \%$ \\
\hline 8 & 91 & - & 93 & 90,5 & 93,5 & 7 & $3,24 \%$ & $98,61 \%$ \\
\hline 9 & 94 & - & 96 & 93,5 & 96,5 & 3 & $1,39 \%$ & $100 \%$ \\
\hline & & & & & & $\mathbf{2 1 6}$ & $\mathbf{1 0 0 \%}$ & \\
\hline
\end{tabular}


Physical activity has an empirical score range of 51 to 85 , so that the range of scores is 34 . The results of data calculations obtained an average of 67.81; standard deviation of 7.46; variance of 55.5871; a median of 67.0; and mode of 65. Grouping physical activity data can be seen in the frequency distribution table as follows. Gallat normality test results of the estimated Y over X obtained the value of $\mathrm{L}_{\text {count }}=0.0408$ this value is smaller than the value of $\mathrm{L}_{\text {table }}(\mathrm{n}=216 ; \alpha=$ 0.05) of 0.060 . Considering that $\mathrm{L}_{\text {count }}$ is smaller than $\mathrm{L}_{\text {table, }}$, the distribution of physical education learning outcomes for physical activity comes from normally distributed populations. While the significance test and regression linearity of physical education learning outcomes on physical activities obtained a regression constant $a=71.63$ and a regression coefficient $b=0.14$. Thus the relationship of the simple regression equation model is $\hat{Y}=71.63+0.14 \mathrm{X} 1$. Before the regression equation model is further analyzed and used in drawing conclusions, first the significance and linearity of the regression equation is tested. The results of the calculations of significance and linearity are arranged in the following ANAVA table.

Table 3. ANAVA Test of Significance \& Linearity of Regression Equations $\hat{Y}=71.63$ $+0.14 X 1$

\begin{tabular}{|l|c|c|c|c|c|}
\hline \multicolumn{1}{|c|}{ Variance } & df & $\begin{array}{c}\text { Sum of } \\
\text { Squares }\end{array}$ & $\begin{array}{c}\text { Mean } \\
\text { Sum of } \\
\text { Squares }\end{array}$ & F & Sig \\
\hline Total & 216 & 1433686 & & & \\
\hline Coefficient (a) & 1 & 1428538.69 & & & \\
\hline Regression (b/a) & 1 & 243.89 & 243.89 & $10.64 * *$ & 0.00 \\
\hline Residual & 214 & 4903.42 & 22.91 & & \\
\hline
\end{tabular}

Information :

**: Regression is very significant $\left(\mathrm{F}_{\text {count }}>\mathrm{F}_{\text {table }}\right)$

ns: Regression is linear $\left(\mathrm{F}_{\text {count }}<\mathrm{F}_{\text {table }}\right)$

df: Degrees of freedom

Regression equation $\hat{\mathrm{Y}}=71.63+0.14 \mathrm{X} 1$, for the significance test obtained $\mathrm{F}_{\text {count }} 10.64$ greater than $\mathrm{F}_{\text {table }}(0.05 ; 1: 214) 3.89$ at $\alpha=0.05$. Because Fcount $>$ Ftable, the regression equation is declared significant. For the linearity test, the $F_{\text {count }}$ of 1.20 is smaller than the $F_{\text {table }}(0.05 ; 33$ : 181) of 1.50 at $\alpha=0.05$. Because $\mathrm{F}_{\text {count }}<\mathrm{Ft}_{\text {able, }}$, the estimated point distribution forming a linear line is acceptable.

The results of testing the hypothesis of the influence of physical activity on physical education learning outcomes obtained by the path coefficient value of physical activity on physical education learning outcomes of 0.152 with a $t_{\text {count }}$ of 2.22 . Because the $t$-value is greater than the table value at $\mathrm{df}=212$ for $\alpha=0.05$ of $1.97, \mathrm{H}_{0}$ is rejected and $\mathrm{H}_{1}$ is accepted, which means there is a positive direct effect of physical activity variables on the variable of physical education learning outcomes.

\section{DISCUSSION}

Previous research conducted by Donnelly et al. (2017) added 90 minutes of MVPA physical activity in one week of school activities, by providing physical activity for 10 minutes each change of class time for students grades 1 through 3. Longitudinal research during 3 years showed an increase in learning outcomes in reading, spelling, mathematics and composite. In a study conducted by Castelli et al. 9-year-old children participate in afterschool physical activity 
programs every day for nine months. The program lasts several hours, involving about 40 minutes of moderate to very active physical activity (MVPA). Children do more moderate to very active physical activity as long as the physical activity program performs better than their peers in the most demanding tasks that require executive functions (EF) from the brain. Its function is to: hypothesized brain processes that control other brain processes. Included in the work of EF is inhibition, memory, attention, flexibility, planning, and problem solving. The results of hypothesis analysis produce findings that physical activity has a direct positive effect on learning outcomes physical education. Based on these findings it can be concluded that the physical education learning outcomes are directly affected positively by physical activity. Increased physical activity will result in increased learning outcomes physical education. The results of this study are in line with the thoutht that physical education is the educational process about and through physical activities, games, and sports chosen to achieve educational goals. Likewise the recommendations from the Centers for Disease Control and Prevention (2010) where physical activity can relieve depression symptoms and improve one's mood. So, if students have good physical activity, it will have an impact on improving learning outcomes while at school, especially on physical education subjects.

The study present has differences and similarities with previous studies, Castelli and Donelly, using physical activity interventions for 9 months to 3 years, measuring the effect of interventions during that time period (longitudinally). While in the present study, physical activity measurements with 7 days PA recall. Longitudinal studies measuring the effect of physical activity in Indonesia so far have not been found by researchers. Thus, opening up space for further research. This can strengthen to reveal whether physical activity has a direct or indirect effect on physical education learning outcomes. Likewise, it is considered to obtain a valid level of physical activity using an accelerometer, as was done through research by the Avon Longitudinal Study of Parents and Children (ALSPAC) which suggests a long-term positive impact of MVPA on academic achievement in adolescence. Physical activity following various studies (Heidi Syväoja et al., 2012) does not directly influence learning outcomes, but through several factors that mediate, such as: brain development and brain function. Examines physical activity from the perspectives of school physical education classes, other physical activity during the school day, leisure-time physical activity, overall physical activity and physical fitness. This study in line with other research on the effects of physical activity on academic achievement, cognitive functions, schooling and mechanisms that may possibly mediate the effects of physical activity on learning. And then also in line with analyses what the research results mean in terms of best practices to increase children's physical activity during the school day increasing physical activity at school. Learning is considered from the perspectives of school grades, cognitive functions (attention, perception, memory and problem-solving), behavior and schooling.

\section{CONCLUSION}

Physical activity has a direct positive effect on learning outcomes Physical education. This means that increasing physical activity will lead to an increase in physical education learning outcomes for students of grade eight. The implication is that the research findings show that physical activity has a direct positive effect on learning outcomes of Physical Education. This means that efforts can be made to improve learning outcomes physical education through physical activity, by providing structured physical activities, games and sports chosen to achieve educational goals. This study still has limitations in revealing the effect of physical activity on 
physical education learning outcomes, limitations in the accuracy of students recalling their physical activities in the last 7 days, teacher assessment components in physical education learning outcomes, and research weaknesses. Therefore further research is needed to obtain the similarity of results that there is the influence of physical activity on physical education outcomes. While for Physical Education Teachers, it is expected to be more concerned in the learning process by developing various activities related to basic movement skills and optimizing all the potentials and experiences of physical education teachers in providing teaching material.

\section{REFERENCES}

Bartholomew, J. B., \& Jowers, E. M. (2011). Physically active academic lessons in elementary children. Preventive Medicine, 52(Suppl), S51-S54.

https://doi.org/10.1016/j.ypmed.2011.01.017

Baumgartner, T., Jackson, A. (Tony), Mahar, M., \& Rowe, D. (2006). Measurement for

Evaluation in Physical Education and Exercise Science (8th ed.). McGraw-Hill

Humanities/Social Sciences/Languages.

Bellarin, M. M. (2016). The Effect of Physical Activity and Exercise on the Academic Achievement of Elementary School Students (Vol. 9). https://doi.org/10.5151/cidi2017-060 Bevans, K. B., Fitzpatrick, L. A., Sanchez, B. M., Riley, A. W., \& Forrest, C. (2010). Physical Education Resources, Class Management, and Student Physical Activity Levels: A StructureProcess-Outcome Approach to Evaluating Physical Education Effectiveness. Journal of School Health, 8O(12), 573-580. https://doi.org/10.1111/j.1746-1561.2010.00544.x

Centers for Disease Control and Prevention. (2010). The association between school based physical activity, including physical education, and academic performance (Vol. 2010). Atlanta. Chen, W., Mason, S., Hypnar, A., \& Bennett, A. (2016). Assessing motor skill competency in elementary school students: A three-year study. Journal of Sports Science and Medicine, 15(1), 102-110.

Committee on Physical Activity and Physical Education in the School Environment. (2013).

Educating the Student Body. In C. H. Kohl HW III (Ed.), Educating the student body: taking

physical activity and physical education to school. https://doi.org/10.17226/18314

Cothran, D. J. P. H. K. (2015). Classroom Management in Physical Education. Journal of

Physical Education, Recreation \& Dance, 57(6), 29-32.

https://doi.org/10.1080/07303084.1986.10606159

Cratty, B. J. (1973). Intelligence in Action: Physical Activities for Enhancing Intellectual

Abilities. Englewood Cliffs, N.J.: Prentice-Hall.

Donnelly, J. E., Ed, D., Co-chair, F., Hillman, C. H., Co-chair, P. D., Ph, D., ... Ph, D. (2017).

Physical activity, fitness, cognitive function, and academic achievement in children: A systematic review. Medicine and Science in Sports and Exercise, 48(6), 1197-1222.

https://doi.org/10.1249/MSS.0000000000000901.Physical

Donnelly, J. E., \& Lambourne, K. (2011). Classroom-based physical activity, cognition, and academic achievement. Preventive Medicine, 52(SUPPL.), S36-S42.

https://doi.org/10.1016/j.ypmed.2011.01.021

Ellemberg, D., \& St-Louis-Deschênes, M. (2010). The effect of acute physical exercise on cognitive function during development. Psychology of Sport and Exercise, 11, 122-126. https://doi.org/10.1016/j.psychsport.2009.09.006

Ericsson, I. R. (2014). Effects of motor skills training and daily physical education: Research results in the Swedish Bunkeflo project. International Journal of Physical Education, 51(2), 19- 
29. Retrieved from

https://search.ebscohost.com/login.aspx?direct=true\&db=eue\&AN=97479191\&site=ehost-live Heidi Syväoja, Kantomaa, M., Laine, K., Jaakkola, T., Pyhältö, K., \& Tammelin, T. (2012).

Physical Activity and Learning. Helsinki.

J Hylok, M. (2011). Exploring Student Perceptions to Explain the Relationship Between Physical Activity and Academic Achievement in Adolescents: A Mixed Methods Study.

Kyan, A., Takakura, M., \& Miyagi, M. (2018). Does physical fitness affect academic achievement among Japanese adolescents? A hybrid approach for decomposing within-person and between-persons effects. International Journal of Environmental Research and Public Health, 15(9). https://doi.org/10.3390/ijerph15091901

Kohl, H.W., \& Cook, H.D. (2013).Educating the student body: Taking physical activity and physical education to school. Washington, D.C.: The National Academic Press

Magistro, D., Bardaglio, G., \& Rabaglietti, E. (2015). Gross motor skills and academic achievement in typically developing children: The mediating effect of ADHD related Behaviours. Cognition, Brain, Behavior, 19(2), 149-163.

Mahar, M. T., Murphy, S. K., Rowe, D. A., Golden, J., Shields, A. T., \& Raedeke, T. D. (2006). Effects of a classroom-based program on physical activity and on-task behavior. Medicine and Science in Sports and Exercise, 38(12), 2086-2094.

https://doi.org/10.1249/01.mss.0000235359.16685.a3

Mercier, K., \& Doolittle, S. (2013). Assessing Student Achievement in Physical Education for Teacher Evaluation. Journal of Physical Education, Recreation \& Dance, 84(3), 38-42. https://doi.org/10.1080/07303084.2013.767721

Nichols, B. (2001). Moving and Learning: The Elementary School Physical Education Experience (3rd ed.). NY: McGraw-Hill College.

Otero, I. R., \& Perez, L. M. R. (2015). Adolescence, motor coordination problems and competence. Educación XX1, 18.2, 189-213. https://doi.org/10.5944/educXX1.14015 Pesce, C., Crova, C., Cereatti, L., Casella, R., \& Bellucci, M. (2009). Physical activity and mental performance in preadolescents: Effects of acute exercise on free-recall memory. Mental Health and Physical Activity, 2, 16-22. https://doi.org/10.1016/j.mhpa.2009.02.001 Resaland, G. K., Aadland, E., Moe, V. F., Aadland, K. N., Skrede, T., Stavnsbo, M., ... Anderssen, S. A. (2016). Effects of physical activity on schoolchildren's academic performance: The Active Smarter Kids (ASK) cluster-randomized controlled trial. Preventive Medicine, 91, 322-328. https://doi.org/10.1016/j.ypmed.2016.09.005

Singh, K. K. (2013). The Impact of Physical Education/Activity and Motor Development on Academic Achievement. SSRN Electronic Journal. https://doi.org/10.2139/ssrn.2231958

Smith, N. J., Monnat, S. M., \& Lounsbery, M. A. F. (2015). Physical Activity in Physical Education: Are Longer Lessons Better? Journal of School Health, 85(3), 141-148.

https://doi.org/10.1111/josh.12233

Tomporowski, P. (2003). Effects of acute bouts of exercise on cognition. Acta Psychologica, 112, 297-324. https://doi.org/10.1016/S0001-6918(02)00134-8

van der Fels, I. M. J., te Wierike, S. C. M., Hartman, E., Elferink-Gemser, M. T., Smith, J., \& Visscher, C. (2015). The relationship between motor skills and cognitive skills in 4-16 year old typically developing children: A systematic review. Journal of Science and Medicine in Sport, 18(6), 697-703. https://doi.org/10.1016/j.jsams.2014.09.007 